\section{Advanced malignant melanoma during pregnancy: technical description of sentinel lymph node biopsy followed by radical lymph node dissection}

\section{Melanoma maligno avançado durante a gravidez: descrição técnica da biópsia de linfonodo sentinela seguida de linfadenectomia radical}

Alberto Julius Alves Wainstein 1

Lívia Cristina Lima Soares Barbosa 2

Milhem Kansaon 3

Marcelo Salomé 4

Ana Paula Drummond-Lage 5

\begin{abstract}
Introduction: melanoma is a very aggressive cancer, with increasing incidence, and is currently the fifth most common cancer in men and the sixth most common in women in the United States. Melanoma is not unusual in pregnancy, with an estimated occurrence rate of 1:1.000. Although not the most common cancer in pregnancy, melanoma is the tumor with the highest incidence of placenta and fetus metastases.

Description: a 29-year-old lady, 4 weeks after conception underwent resection of an atypical pigmented lesion after a diagnosis of stage T4b melanoma. At 16 weeks she underwent a broad local excision and sentinel lymph node (SLN) biopsy. SLN was evaluated histologically and tested positive for melanoma. A radical axillary lymphadenectomy was performed on the patient without evidence of metastasis in any other LN. In the 40th week of pregnancy, labor was induced and a healthy newborn was delivered via cesarean.

Discussion: melanoma management in pregnancy is more complex and requires multidisciplinary coordination, as well as extensive discussion with the patient and her family. We present a case report description in which treatment recommendations are established according to no pregnancy experience.
\end{abstract} Key words Surgery, Tumor, Pregnancy, Lymph node excision

\section{Resumo}

Introdução: o melanoma é um câncer muito agressivo, sua incidencia vem aumentando, e é atualmente o quinto câncer mais comum em homens e o sexto mais comum em mulheres nos Estados Unidos. O melanoma não é incomum na gravidez, com uma taxa de ocorrência estimada em 1: 1.000. Apesar de não ser o câncer mais comum na gravidez, o melanoma é o tumor com maior incidência de metástases da placenta e do feto.

Descrição: paciente de 29 anos foi submetida à ressecção de lesão pigmentada, tendo o diagnóstico de melanoma atípico T4b, quatro semanas após a concepção. Com 16 semanas de gravidez paciente foi submetida a alargamento de margens e biópsia de linfonodo sentinela (SLN). SLN foi avaliado histologicamente sendo positivo para melanoma. A paciente foi então submetida à linfadenectomia axilar radical, sem evidências de metástase em outros linfonodos. $\mathrm{Na}$ $40^{a}$ semana de gravidez, o parto foi induzido, e por cesárea, nasceu um menino saudável.

Discussão: a abordagem do melanoma na gravidez é mais complexa e exige uma coordenação multidisciplinar, bem como uma ampla discussão com a paciente e sua família. Apresentamos uma descrição do caso onde as recomendações de tratamento foram estabelecidas de acordo com a experiência em pacientes não grávidas.

Palavras-chave Cirurgia, Tumor, Gravidez, Linfadenectomia 


\section{Introduction}

Cutaneous melanoma is a serious medical condition that is a growing problem around the world. Increasing incidence of melanoma exceeds that of all other malignancies. The financial and life cost of treating this disease is becoming increasingly burdensome. Early detection and curative surgery are thus critical for minimizing the severity and mortality of melanoma and for reducing healthcare and life costs. ${ }^{1}$

The majority of cancers diagnosed during pregnancy are in the breast, cervical, lymphomas, leukemia or melanoma. Melanoma represents 2 to $3 \%$ of all malignant tumors and is responsible for $8 \%$ of all cancers in pregnancy, and is one of the main causes of cancer death among women of reproductive age. ${ }^{2}$ Although not the most common cancer in pregnancy, with an estimated occurrence rate of 1:1.000, melanoma is the tumor with the highest incidence of placenta and fetus metastases. Estimated incidence of pregnancy complications generated by melanoma varies from 0.1 to 2.8 in every 1000 pregnancies, even though the data in this population has not been systematically checked. ${ }^{3}$

\section{Description}

A 29-year-old woman, Fitzpatrick scale III, 4 weeks after conception, noticed a change in a congenital lesion on the right forearm. The lesion was diagnosed, after biopsy, as melanoma. The patient was aware of the poor prognosis of melanoma and, out of a non-rational instinct to save her unborn child, she decided to conceal the diagnosis from her family and avoid medical treatment. At 16 weeks of pregnancy she came to our service with a recurrent pigmented lesion developing nodules at the site of previous resection. Initial biopsy showed nodulation with recurrent melanoma of approximately $4 \mathrm{~mm}$ in Breslow thickness, Clark level IV, with compromised margin, mitotic index of 7 mitoses per $\mathrm{mm}^{2}$, ulcerated and staged as pT4aNXMX. The patient had a family history of melanoma without any other related comorbidity.

A pathological investigation of the tumor block suggested it was a blade spitzoide melanocytic lesion, favouring Spitz nevus, without discharging nodular melanoma. The case was discussed with the patient and her family and the decision was made to perform a wide margin enlargement and Sentinel Lymph Node Biopsy (SLNB) under local anesthesia and venous sedation. Margin enlargement confirmed melanoma in the vertical growth phase, Clark's level IV, invasion of the reticular dermis, with a maximum thickness of $3.45 \mathrm{~mm}$ without intratumoral or peritumoral inflammatory infiltration, with 8 mitoses per $\mathrm{mm} 2$. There was no ulceration or regression, but a rare angiolymphatic embolus was present and the side and deep margins were free of disease (Figure $1)$.

An ultrasound scan revealed a well-developed fetus of 23 weeks with normal placenta and amniniotic fluid volume. Patient serum LDH was measured and the result was normal.

Preoperative lymphoscintigraphy was performed prior to surgery. On the day of the surgery, a dose of $0.3 \mathrm{mCi}$ of technetium Tc $99 \mathrm{~m}$ sulfur colloid $0.2 \mathrm{~mL}$ in volume was injected into the pericicatricial area. An additional small volume of isosulfan blue dye,

Figure 1

Images of the anatomopathological examination stained with hematoxylin and eosin (HE).

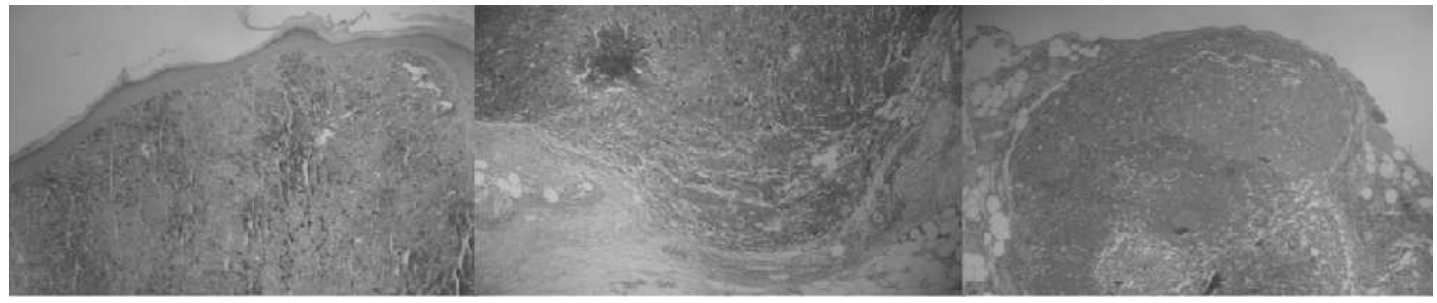

A

B

C

(A) primary recurrent lesion with exophytic nodule showing atypical melanocytes of epithelioid appearance, extensive cytoplasm with variable melanin content, intensive in parts. Nuclei enlarged and rounded or oval, often with prominent nucleoli and mitotic figures; $(B)$ shows the area of margin expansion with neoplastic niche in the deep dermis infiltrating to the subcutaneous tissue The cells have the same appearance as on the first biopsy and may indicate a deep residual tumor or a microscopic satellite; (C) histological examination of the sentinel lymph node showing several niches of intramedullary and sub-capsular melanoma. 
$0.1 \mathrm{~mL}$, was injected into several spots around the lesion to facilitate intraoperative visual identification of SLN. A handheld gamma probe was used transcutaneously to identify SLNs; this is usually done 30 minutes to 4 hours after local injection. A 2$\mathrm{cm}$ incision was then made directly overlying the areas of increased radioactivity, and the SLN was dissected carefully and sent for histopathological evaluation by way of hematoxylin and eosin stain (HE stain). The SLN analysis showed melanoma metastases in the sub-capsular and intramedullary region and the patient was staged as T4bN1aMx.

A right axillary radical lymphadenectomy was indicated and performed under general anesthesia in an obstetric hospital. Despite free margins, the primary lesion resection was expanded to obtain adequate free margins of at least $2 \mathrm{~cm}$ in all directions. There were no residual segments from the atypical melanocytic lesion in this new margin expansion. A total of 32 lymph nodes were resected during the axillar lymphadenectomy, including 24 of levels I and II and 8 of levels III. There was no evidence of metastasis in any lymph node. The patient was staged as T4N1aMo, stage III.

In the $40^{\text {th }}$ week of pregnancy, labor was induced, and a healthy newborn was delivered via cesarean. The cesarean was chosen by the obstetrician and the patient without strict medical indication, as patient was experiencing great stress as a result of the previous procedures. Careful macroscopic and histological examination of the placenta, umbilical cord and chorionic villous did not reveal any melanoma metastasis. After delivery, the patient underwent a full thorax and abdomen computer tomography, which revealed no lesions. The final staging assessment was carried out 4.5 years after the initial diagnosis and no signs of recurrence were found.

\section{Discussion}

Malignant melanoma is the most aggressive form of skin cancer with an increasing incidence over the past decade. Invasive melanoma is more prevalent among females aged between 0 and 39 years. 4 About 30 to $35 \%$ of women with melanoma are of childbearing age at the time of diagnosis.

For several years, it was widely held that the prognosis of melanoma was worse during pregnancy and that subsequent pregnancies increase the risk of recurrence. 5 The effects of pregnancy and hormone use on melanoma prognosis have been discussed in the literature since 1951.5 Case reports of rapid transformation of nevi into melanoma, the abrupt onset of melanomas, and the low survival rate among pregnant women have led to the hypothesis that pregnancy may, probably through the action of hormones, negatively influence the prognosis of melanoma. However, there is no scientific evidence to corroborate these concepts. Prognosis, recurrence and incidence of melanoma seem to be unaffected by pregnancy. 6 A population-based study conducted by O'Meara et al. ${ }^{7}$ did not find supporting data to conclude that pregnancy is associated with more advanced stage, thicker tumors, increased metastasis to lymph nodes, or a lower survival rate.

Although melanoma is the most common maternal malignant tumor to spread to the placenta, the occurrence of this is very rare. Between 1918 and 2002, melanoma was the cancer most commonly found to involve the placenta and fetus. A literature review reveals 87 cases of placental/fetal involvement with maternal malignancies. Of these 72 (83\%) reported placental involvement only, 10 (11\%) reported fetal metastasis without placental examination, and $5(6 \%)$ reported both placental and fetal metastases. ${ }^{8}$ Microscopic evaluation of the placenta was performed in 24 of 27 patients, and placental involvement was documented in all 24. Six of the 27 reports found fetal metastasis, but 3 reports did not document corresponding placental involvement. 8

Children with clinical evidence of maternally derived metastases have a poor prognosis: death can occur within three months of diagnosis. Newborns with concomitant placental involvement but no clinical evidence of disease should thus be considered a high-risk population. Adjuvant treatment of babies born of women with placental metastasis of melanoma has not been reported. 8 One of the best approaches for preventing fetal involvement is full maternal staging and appropriate treatment, including SLN biopsy and radical lymph node dissection when indicated.

Melanoma management in pregnancy is more complex and requires multidisciplinary coordination, as well as extensive discussion with the patient and her family. Decision-making should be based on: a) the impact of pregnancy on the outcome of melanoma; b) gestational age and risk of metastasis to the placenta and fetus; c) safety of radiological diagnostic tests and d) treatment options during pregnancy. 9

Staging and treatment of pregnant women with local or distant metastases of melanoma are not well defined and there are no specific directions for imaging studies. Adjuvant treatments such as interferon- $\alpha-2 b$ or Pegylated Interferon are not well established. There is no consensus as to the effect on 
the fetus of therapeutic drugs such as dacarbazine. Promising new drugs for melanoma, such as BRAF and MEK inhibitors, immune agents and others, have not been evaluated for safety and effectiveness in pregnant women. ${ }^{10}$

Sentinel lymph node biopsy can be safely performed in pregnancy, preferably after the first trimester to minimize risks to the developing fetus. 10 This includes the use of radioisotopes such as technetium-99 with minimal amounts of exposure to ionizing radiation for the pregnant woman, the fetus and the surgical team. When indicated, radical lymph node dissection may be an important and safe approach during pregnancy because the risk and surgical management during pregnancy are already well established.

\section{References}

1. Oduncu FS, Kimmig R, Hepp H, Emmerich B. Cancer in pregnancy: maternal-fetal conflict. J Cancer Res Clin Oncol. 2003; 129: 133-46.

2. Leon SP, Mihm MC Jr, Murphy GF, Hoon DS, KashaniSabet M, Agarwala SS, Zager JS, Hauschild A, Sondak VK, Guild V, Kirkwood JM. Progression of cutaneous melanoma: implications for treatment. Clin Exp Metastasis. 2012; 29 (7): 775-96

3. Alexander A, Samlowski WE, Grossman D, Bruggers CS, RM, Zona JJ, Noyes RD, Bowen GM, Leachman SA. Metastatic melanoma in pregnancy: risk of transplacental metastases in the infant. J Clin Oncol. 2003; 21: 3670.

4. Weir HK, Marrett LD, Cokkinides V, Barnholtz-Sloan J, Patel P, Tai E, Jemal A, Li J, Kim J, Ekwueme DU. Melanoma in adolescents and young adults (ages 15-39 years): United States, 1999-2006. J Am Acad Dermatol. 2011; 65 (5 Suppl. 1): S38-49.

5. Pack GT, Sharnagel IM. Prognosis of malignant melanoma and pregnant women. Cancer 1941; 4: 324-34.

6. Broer N, Buonocore S, Goldberg C, Truini C, Faries MB, Narayan D, Ariyan S. A proposal for the timing of management of patients with melanoma presenting during pregnancy. J Surg Oncol. 2012; 106: 36-40.
Malignant melanoma is not uncommon during pregnancy. As early diagnosis may lead to cure, it is essential that all physicians who care for pregnant women understand this disease. Obstetricians should conduct a full skin examination of all body areas during evaluation of the pregnant women or request a dermatological consult and any suspicious nevi should be biopsied. Treatment of early stage melanoma is the same irrespective of whether or not the patient is pregnant. Preoperative lymphoscintigraphy and SLN biopsy can be performed safely in pregnant women. Despite the high risk of the disease and the various procedures the patient underwent, she and her son exhibit no signs of metastatic melanoma after 4.5 years of follow-up.

7. O'Meara AT, Cress R, Xing G, Danielsen B, Smith LH. Malignant melanoma in pregnancy. A population-based evaluation. Cancer 2005; 103: 1217-26.

8. Jhaveri MB, Driscoll MS, Grant-Kels JM. Melanoma in pregnancy. Clin Obstet Gynecol. 2011; 54: 537-45.

9. Mathew M, Sheik S, Rao K, Burney IA, Sawhney S, AlHamdani A. Metastatic Malignant Melanoma during pregnancy. Case report and review of the literature. SQU Med J. 2009; 9: 79-83

10. Eggermont AMM, Chiarion-Sileni V, Grob JJ, Dummer R, et al. Adjuvant ipilimumab versus placebo after complete resection of high-risk stage III melanoma (EORTC 18071): a randomised, double-blind, phase 3 trial. Lancet Oncol. 2015; 6: 522-30.

Recebido em 3 de junho de 2015

Versão final apresentada em 8 de setembro de 2015

Aprovado em 1 de outubro de 2015 